\title{
Algae Fuels as an Alternative to Petroleum
}

\author{
Evan Stephens ${ }^{1,2 *}$, Rocky de Nys ${ }^{3,4}$, lan L Ross ${ }^{1,2}$ and Ben Hankamer ${ }^{1,2}$ \\ ${ }^{1}$ The University of Queensland, Solar Biofuels Research Centre, Queensland, Australia \\ ${ }^{2}$ The University of Queensland, Institute for Molecular Bioscience, Queensland, Australia \\ ${ }^{3}$ James Cook University, School of Marine and Tropical Biology, Queensland, Australia \\ ${ }^{4}$ James Cook University, Centre for Sustainable Tropical Fisheries and Aquaculture, Queensland, Australia
}

\begin{abstract}
Here we examine the scale of petroleum consumption and the current lack of scalable petroleum alternatives. We highlight the contribution that macroalgae and microalgae can collectively make as feedstocks in the future energy mix, discuss recent advancements and current development pathways, and consider the potential and the limitations of these production systems for economic and environmental sustainability moving towards a scale of $10-20 \%$ of global petroleum consumption.
\end{abstract}

Keywords: Macroalgae; Microalgae; Fossil fuel; Biofuels; Bioproducts; Feedstock

\section{Introduction}

The scale of global fossil fuel consumption is massive. In 2011 almost 11,000 million tons of oil equivalent (Mtoe) were consumed in the form of oil, gas, and coal-based fossil fuels [1]. While fossil fuel consumption continues to increase ( $32 \%$ increase from 2000 to 2011 ) to sustain our growing population and the advancement of developing nations (e.g. China and India), most of this increase in consumption comes from coal ( 57\% increase $2000-2011)$ and natural gas $(\sim 34 \%$ increase 2000-2011). Coal and gas production rates are currently increasing faster than consumption rates (figure 1) [1]. For petroleum oil however, consumption ( 14\% increase 2000-2011) has grown faster than oil production ( 10\% increase $2000-2011)$ [1] in the same period largely due to the plateau in production of conventional oil; a harbinger of some major challenges and changes to the future energy mix.

The petroleum industry can exploit a range of feedstocks for the production, processing and transformation of liquid hydrocarbons, of which conventional oil has, until recently, been the cheapest and most readily accessible. Currently, we are witnessing a necessary transition to a more diverse mix of feedstocks. A significant factor in the choice of future feedstocks will be the impact on global $\mathrm{CO}_{2}$ emissions [2] for which targets have been set by many governments suggesting a trend that is likely to increase. If effective, these targets would impose a market premium increasingly favouring $\mathrm{CO}_{2}$-neutral feedstocks, including fuels derived from algae. The technology of producing biocrude and more specific oils from algae has recently made significant progress in addressing economic obstacles and the scalability of photoautotrophic algae production is arguably high (up to $\sim 10-20 \%$ of global fuel consumption), when water and nutrient recycling strategies are employed. Here we discuss how algae can contribute to the renewable production of biofuels and bioproducts relative to other sources.

\section{Global Fuel Consumption}

Hydrocarbon based fuels represent $\sim 80 \%$ of our global energy consumption $[1,3]$. In comparison, biofuel technologies promoted as a means to address fuel security and climate change concerns, currently represent only $\sim 0.6 \%$ of global fuel consumption [1]. Supply of first generation biofuels such as corn ethanol and rapeseed derived biodiesel have increased substantially, but this has been accompanied by a food versus fuel debate $[4,5]$ which has now manifested as real world concerns, as biofuel production volumes from such sources are already threatening global food security [6,7]. Petroleum derived oil represents $\sim 56 \%$ of global fuel consumption and the scale of this enormous consumption $\left(\sim 4.1 \times 10^{9} \mathrm{~T}\right.$ in 2011) [1] presents an issue of scalability to advocates of biofuel and bioenergy technologies. Global production of the main food products in 2010 totalled $\sim 7.6 \times 10^{9} \mathrm{~T}$ [8] yet the embodied energy of our global food harvest is dwarfed by the energy we consume from petroleum (Figure 2) which is around three times greater. Combined with the energy losses associated with processing biomass into energy dense fuels, any attempt to generate a globally significant contribution to petroleum alternatives with food crops or with systems that divert energy from food production, will incur significant economic and social impacts that must be properly evaluated and planned for.

The extraction of petroleum oil is becoming more costly and problematic $[9,10]$ as easily extracted reservoirs are depleted. Ironically, the unprecedented prospect of complete arctic ice loss in the summer [11] is opening up new opportunities for oil exploitation, as well as other deep sea prospects (now $\sim 70 \%$ of new oil discoveries are in the deep sea [10]). The technical challenges of liberating unconventional petroleum resources and the prospect of increasing oil prices (predicted rises to $\sim$ US $\$ 120-140 \mathrm{bbl}^{-1}$ by $2035[12,13]$ ) are indeed stimulating technology development in response. It remains controversial as to whether conventional oil production has peaked (largely depending on how "conventional oil" is defined). Predictions range from optimistic estimates of continued increases in production (e.g. [12,13]) through to more polarised debates such as those summarised by Kerr [14-17]. At some point, it is assumed, that climate change related effects, particularly temperature rise and precipitation changes (with corresponding effects on food production), must heighten concerns not only over the effects of climate change but its real economic cost

*Corresponding author: Evan Stephens, The University of Queensland, Solar Biofuels Research Centre, Queensland, Australia, E-mail: e.stephens@imb.uq.edu.au

Received June 21, 2013; Accepted July 22, 2013; Published July 28, 2013

Citation: Stephens E, de Nys R, Ross IL, Hankamer B (2013) Algae Fuels as an Alternative to Petroleum. J Pet Environ Biotechnol 4: 148. doi:10.4172/21577463.1000148

Copyright: (c) 2013 Stephens E, et al. This is an open-access article distributed under the terms of the Creative Commons Attribution License, which permits unrestricted use, distribution, and reproduction in any medium, provided the original author and source are credited. 
Citation: Stephens E, de Nys R, Ross IL, Hankamer B (2013) Algae Fuels as an Alternative to Petroleum. J Pet Environ Biotechnol 4: 148 doi:10.4172/2157-7463.1000148

Page 2 of 7

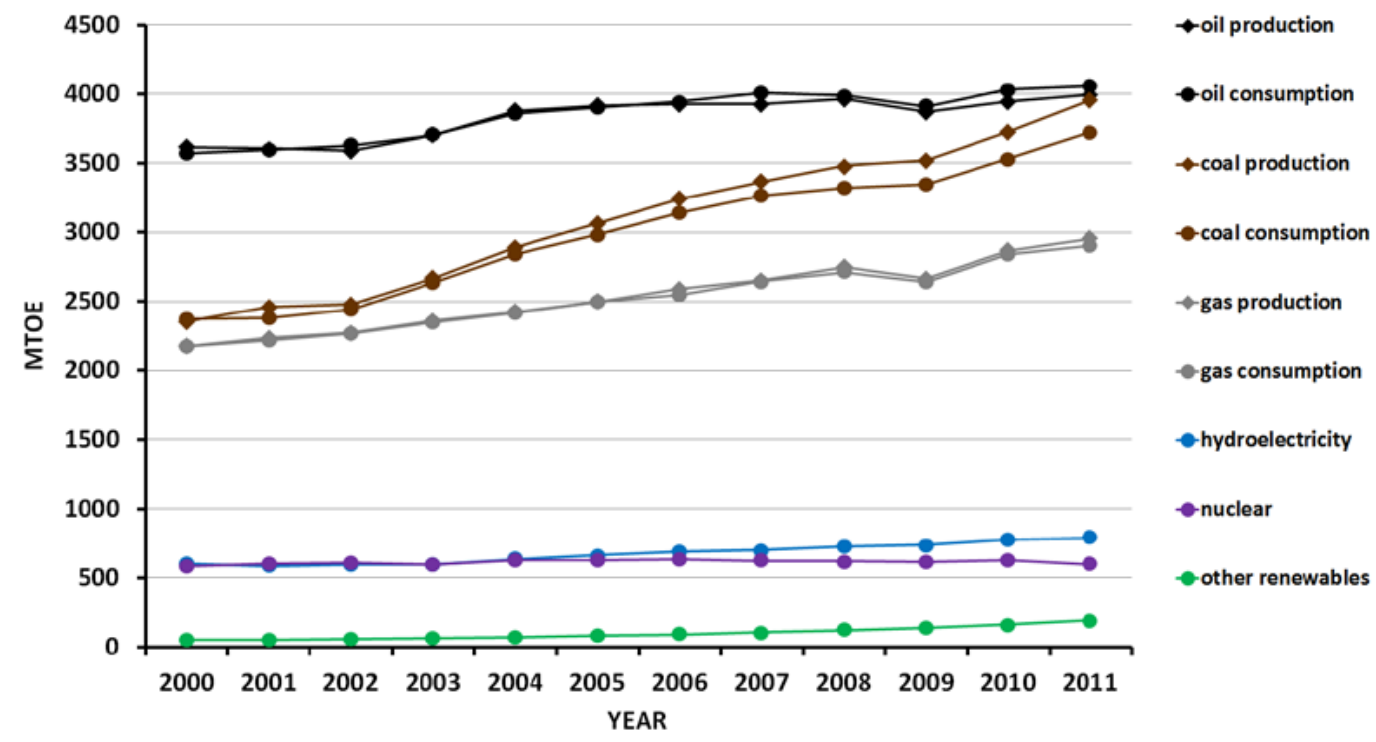

Figure 1: Energy production/consumption since 2000. Data from BP Statistical Review of World Energy 2012 [1]. It should be noted that values for hydroelectricity, nuclear, and other renewables (which are generally direct electricity generating technologies) are represented by BP data as Mtoe values through the application of a $38 \%$ thermal efficiency conversion factor.

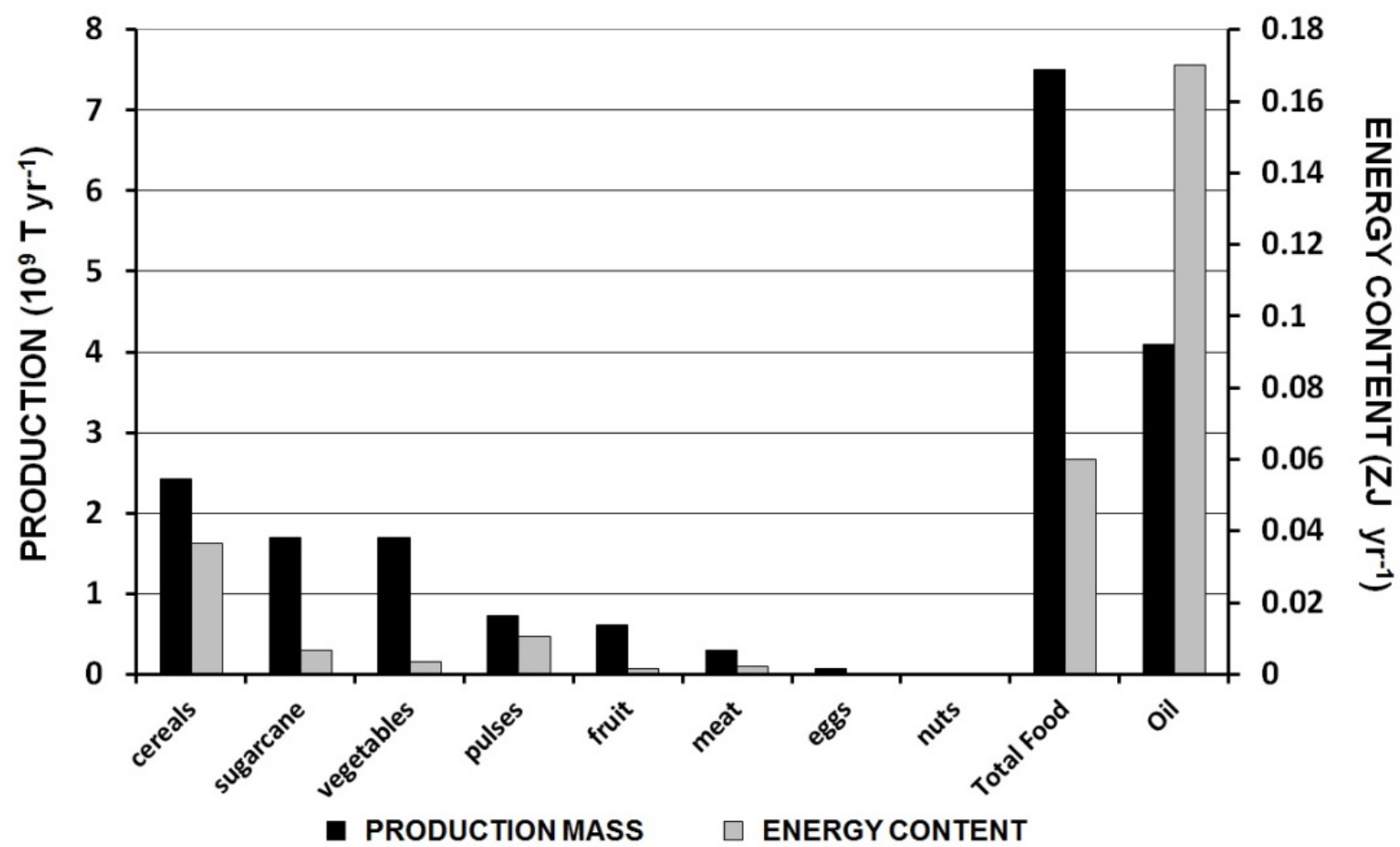

Figure 2: Global Energy Production from Petroleum and Food Products. The conversion of crop biomass to energy dense oils or fuels results in a loss of $\geq 50 \%$ of embodied energy. Food crops cannot therefore replace a globally significant proportion of energy as oil, without dramatically increasing pressure upon food security. The data presented for oil is sourced from BP Statistical Review of World Energy 2012 [1] and for food data is sourced from FAOSTAT [8], with general food calorific values calculated as previously by Stephens et al. [43]

e.g. costs of reduced crop yields, damage from extreme weather events and adaptation of communities [18,19]. Subsequently, an obvious social response will be an increasingly vocal promotion of legislative action to limit $\mathrm{CO}_{2}$ emissions, in part by shifting to renewable fuels and renewable electricity generation. The two non-renewable options for alleviating this pressure are effective and economical $\mathrm{CO}_{2}$ capture and sequestration technologies, and a massive expansion of nuclear power, neither of which appears to be making dramatic progress at present. In the absence of such progress, claims that the majority of fossil fuels must be left in the ground rather than combusted [20] are 
indeed sobering, and alternative carbon-neutral production sources for energy and fuel are necessary.

\section{Renewable Energy Systems}

Hydroelectric schemes are among the most successful renewable energy technologies and their global energy output has increased at an average and relatively consistent rate of $\sim 3 \% \mathrm{yr}^{-1}$ for the past 50 years [1]. Other renewable technologies such as solar photovoltaic/thermal and wind energy, have only recently been effectively deployed (almost 30 -fold and 15-fold increase respectively from 2000 to 2010 [1]). Nonetheless, they are yet to reach globally significant levels (currently $\sim 0.1 \%$ and $0.8 \%$ respectively, of current global energy consumption [1]). Though a welcome trend, most renewable energy systems target electricity, which only represents $\sim 20 \%$ of our current energy consumption, and the need for energy dense, transportable fuels still remains. Even if increased electrification of our energy consumption can be achieved (increasingly likely with the emergence of new battery technologies such as the lithium-air batteries in development by IBM and collaborators [21]), transition from our current fuel consumption rates will take considerable time, effort, and cost.

Regardless of the future energy mix, there is an inextricable link between the transport of goods and people that requires high-energy density liquid fuels, at least into the foreseeable future. Second generation or advanced biofuel technologies (i.e. those that do not compete for arable land or with food crops) are being considered globally as the successor to fossil derived liquid fuels. However some biofuel technologies (heterotrophic oil production from carbohydrate feedstocks, and farnesene from sugar) are essentially carbon conversion methods and while they may boast impressive technology systems and can produce valuable demand-driven bioproducts, they draw from the existing energy and carbon pools of our primary production (i.e. first generation feedstocks). These heterotrophic systems do not directly capture solar energy at high efficiency and their scalability and ultimate global significance for energy solutions is therefore limited [3] just as first generation biofuel systems have been (e.g. corn ethanol). If such conversion technologies utilize second generation feedstocks or waste streams then they would be much more sustainable and scalable.

Next generation biofuel systems that have less need for arable land and freshwater (and hence greater scalability) are in development (e.g. algae production and lignocellulosic processing of more abundant biomass sources) but while the technical challenge of 'spinning straw into gold' appears surmountable, the expense of these technologies has so far placed them outside of affordable reality ( 2 to 10 times the current cost of production for petroleum oil). Further, issues of sustainability may be mitigated - but not avoided entirely. It is clear that to ultimately be both environmentally sustainable and scalable to globally significant levels, algae biomass systems for large scale fuel production must be photoautotrophic (or employ waste streams that would otherwise generate $\mathrm{CO}_{2}$ ), and must not compete with production of food crops.

\section{Algae Production}

The production of macroalgae and microalgae (Figure 3 and Table 1) utilise established technologies which have been practiced commercially for decades, primarily for waste water treatment and the production of food products for direct consumption, phycocolloids, nutraceuticals and other high value products (HVPs). The production of macroalgae in open ponds and coastal seawaters, and microalgae in high rate ponds (HRPs) and photobioreactors (PBRs) can achieve much higher yields than terrestrial crops $[3,22,23]$, but the high capital cost of establishment has traditionally prevented the production of algal biomass at the low costs required for economically sustainable commodity fuel production.

Table 1 does not capture all relevant issues; for example algal systems are much more expensive to establish, operate and harvest than agricultural sugar cane, though more productive (see below) and more efficient in nutrient (due to prevention of leachate and nutrient

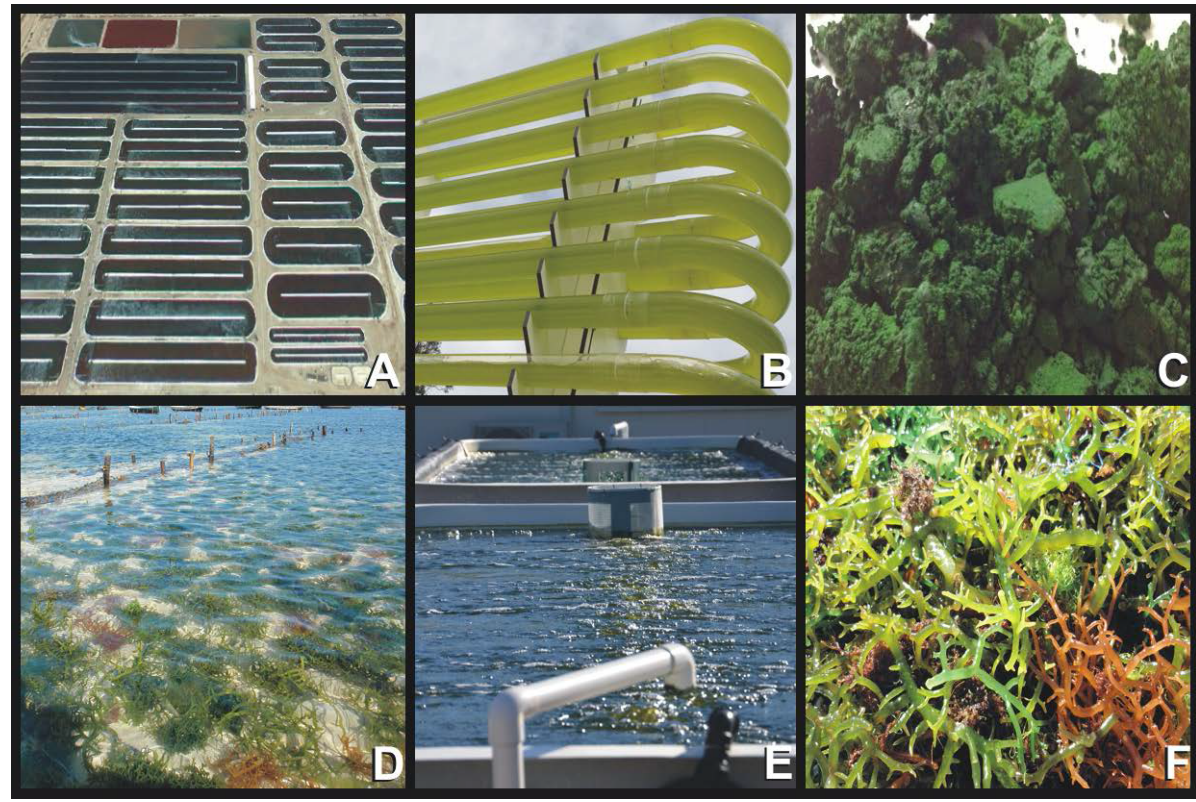

Figure 3: Microalgae and Macroalgae. (A) microalgae high rate pond cultivations of Spirulina (Earthrise farms in California USA) [65]; (B) microalgae cultivated in photobioreactors (example depicted is LGem tubular system at Solar Biofuels Research Centre, Australia) can have higher yields for specialty bioproducts[66]; (C) freshly harvested microalgal biomass[66]; (D) macroalgae coastal cultivations of Kappaphycus [67]; (E) macroalgae cultivation of Ulva in open ponds can be scaled to large ponds on land [68]; (F) freshly harvested macroalgal biomass [67]. 


\begin{tabular}{|c|c|c|c|}
\hline & Macroalgae & Microalgae & Sugarcane \\
\hline Production Yield & $\sim 50-110 \mathrm{~T} \mathrm{ha}^{-1} \mathrm{yr}^{-1}$ dry weight $[22,23,69,70]$ & $\sim 70-100 \mathrm{~T} \mathrm{ha}^{-1} \mathrm{yr}^{-1}$ dry weight [38] & $\sim 71 \mathrm{~T} \mathrm{ha}^{-1} \mathrm{yr}^{-1}$ wet weight $[8]$ \\
\hline Oil content $\%$ w/w & up to $10 \%[61,71]$ & up to $30 \%$ (or more) [72] & $\mathrm{N} / \mathrm{A}$ \\
\hline Standard Calorific Value & $\sim 5-20 \mathrm{MJ} \mathrm{kg}^{-1}[27,73]$ & $\sim 20-25 \mathrm{MJ} \mathrm{kg}^{-1}[33,74]$ & $\sim 3.9 \mathrm{MJ} \mathrm{kg}^{-1}$ \\
\hline Calculated Captured Solar Energy (CCSE) & $\sim 0.2-2.2 \mathrm{TJ} \mathrm{ha}^{-1} \mathrm{yr}^{-1}$ & $\sim 1.4-2.5 \mathrm{TJ} \mathrm{ha}^{-1} \mathrm{yr}^{-1}$ & $\sim 0.3 \mathrm{TJ} \mathrm{ha}^{-1} \mathrm{yr}^{-1}$ \\
\hline Photosynthetic Conversion Efficiency (PCE) & up to $3.0 \%$ & up to $3.4 \%$ & $\sim 0.4 \%$ \\
\hline Oil/Fuel Potential & $\begin{array}{l}\text { HTL to biocrude } \\
125-1100 \mathrm{GJ} \mathrm{ha}^{-1} \mathrm{yr}^{-1}\end{array}$ & $\begin{array}{c}\text { HTL to biocrude } \\
700-1250 \mathrm{GJ} \mathrm{ha}^{-1} \mathrm{yr}^{-1}\end{array}$ & $\begin{array}{l}\text { Ferment/distill to ethanol 100 GJ } \\
\qquad \text { ha }^{-1} \mathrm{yr}^{-1}\end{array}$ \\
\hline
\end{tabular}

Table 1: Comparative Assessment of Macroalgae and Microalgae. HTL = Hydrothermal liquefaction; PCE calculated as CCSE/20 MJ m ${ }^{-2} \mathrm{~d}^{-1} @ 365 \mathrm{~d}$ yr ${ }^{-1}$ solar energy (in regions where similar yields are obtained with lower average solar energy $<20 \mathrm{MJ} \mathrm{m}^{-2} \mathrm{~d}^{-1}$ then PCE rates might be reasonably up to $30 \%$ higher, but much below $15 \mathrm{MJ}$ $\mathrm{m}^{-2} \mathrm{~d}^{-1}$ and output would be expected to be adversely affected); HTL conversion efficiency for assumed at $50 \%$; ethanol energy output calculated as $71 \mathrm{~T}^{-1} \mathrm{yr}^{-1}$ harvest $\mathrm{x}$ $\sim 80 \%$ for 'burn \& crop' output x $1.7 \mathrm{GJ}$ ethanol per tonne $=\sim 100 \mathrm{GJ} \mathrm{ha}^{-1} \mathrm{yr}^{-1}$.

recycling) and freshwater usage (for saline and wastewater systems freshwater consumption can be $\sim 10$-fold lower than conventional crops) [24]. Though macroalgae potential fuel/energy output is lower than that for microalgae, the capital and operating costs (especially harvesting $[25,26])$ associated with mass cultivation can be considerably less costly in some production models.

\section{Obstacles to commercialization of algae fuels}

The dream of algae fuels is a good one; massive algae farms absorbing $\mathrm{CO}_{2}$ from the atmosphere and from our industrial emissions, to produce biomass at high efficiency. This biomass could be used for thermochemical conversion $[27,28]$ or for biochemical derivation to produce liquid fuels [24]. The carbonaceous biomass residues can either be digested or gasified to $\mathrm{CH}_{4}$ or $\mathrm{H}_{2}[29,30]$ which can then be used to power the process or to generate nitrogenous fertilisers to make the process more sustainable. Furthermore, nutrient recycling is more efficient than in conventional agriculture allowing the potential for production of other bioproducts, and applications such as wastewater treatment and bioremediation.

The reality, as usual, is a lot tougher than the dream, despite the projections of over-sellers and the cheerleaders [31] who claim overestimated productivities and deliver premature promises of commercial success. While energy return on investment (EROI) can be sufficiently high in well designed production models (greater than that of tar sands oil extraction for example), economic sustainability remains the primary challenge [27,32].

The high capital cost of establishing algae farms, both for growth systems and for downstream processing equipment, is a primary economic factor in the cost of biocrude/oil production. The reduction of initial CAPEX and the improvement of biomass productivity are both primary effectors in sensitivity analysis of the economics [33]. The growth of algae in land-based aquatic systems necessitates high rates of water transfer and the high water content of algae biomass can also present challenges in achieving economical dewatering with low energy inputs. Water sustainability (due to evaporation losses) has been highlighted as an issue for mass cultivation of algae [34], although water sustainability is similarly a concern for other primary production systems [35-37] and with the use of saline and waste water resources algae biomass can be produced with around 10 times less freshwater for microalgae than many conventional crops [38] and even less freshwater required for macroalgae cultivation. Nevertheless, for the large scale of production required to contribute $\sim 10 \%$ or more of global fuel use, good water management practices must be engaged and access to sufficient sources of suitable water must be ensured $[39,40]$. Importantly, the vast majority of the world's 15 million tonne per annum production of macroalgae, valued at US\$8 billion (at costs of $\sim$ \$350-3,500 $\mathrm{T}^{-1}[41]$ ), is produced in-sea with natural flow delivering the requisite supply of nutrients and $\mathrm{CO}_{2}$. The scalable production here is substantial and utilises well developed automated technologies in use across temperate and tropical climates [26,42]. At the large scales of production required to achieve significant global impact, the mass cultivation of microalgae can be limited by the availability of sources of enriched $\mathrm{CO}_{2}$ and by the availability of major nutrients (nitrogen and especially phosphorous) [43]. One advantage of macroalgae is that it is less constrained by these limitations, as the vast majority (currently $>95 \%$ ) of macroalgae production is produced in-situ in the oceans with no use of added nutrients or freshwater.

It should be emphasised that the potential carbon neutrality of advanced biofuel production is not currently attributed a value, and thus price comparisons against fossil fuel resources are skewed. A balanced techno-economic and life-cycle comparison would need to impose carbon capture and storage (CCS) costs upon fossil fuels, such that the carbon balance is similar to carbon neutral fuel production systems, for a true 'apples to apples' assessment. Furthermore for a true comparison fossil fuel subsidisation should also be noted. The global cost of subsidising gasoline, diesel and kerosene exceeds US $\$ 500$ billion per year [44]. To put this into context, this is considerably more than Greece's national debt (\$331 billion) [45].

\section{Current Advancement in Expanding Global Algae Cultivation}

Algae production technologies continue to advance and old paradigms are being challenged, with new production strategies emerging for both microalgae [3] and macroalgae [46,47]. Both macroalgae and microalgae show considerable potential for integration with other systems [33,48-52] and this is arguably an attractive path towards early commercialisation, especially given the potential for mitigation of waste from other production outputs (e.g. $\mathrm{CO}_{2}$ emissions from industry and waste water, and nutrient waste loads from agriculture, aquaculture, and other industries). However, while the ambition to develop dedicated fuel production systems from algae is more economically challenging, it is also being pursued and is a primary path towards globally significant scales of production (as energy production will most likely saturate markets of protein feedstocks, HVPs, and other applications). For microalgae, harvesting has received considerable attention [25,53], and the ongoing discovery of endogenous bioactives (e.g. dinoflagellate biotoxins) [54] as well as recent development of engineered HVPs including pharmaceuticals [55,56] demonstrates the potential of natural algae biodiversity and genetic engineering for valuable algae bioproducts.

Hydrothermal liquefaction (HTL) of whole algal biomass $[27,28]$ to biocrude is being adopted as an option for improving the economics and energetics over conventional production models. HTL is a thermochemical processing of biomass at high pressure and temperature and importantly, can be operated with wet biomass slurries 
of $\geq 15 \%$, minimising the need for intensive dewatering. But while this strategy is promising it is not without its technical challenges. Although traditional and expensive dewatering and extraction processes for oil rich algae are avoided in this HTL approach through the processing of whole biomass, the oil content and general composition of the biomass still impacts on biocrude quality (e.g. energy density). However, this process is the conversion method of choice for macroalgae which have a lower oil yield, and therefore energy density but higher productivity per unit area. Though the energy density of HTL algae biocrude of $\sim 32$ $35 \mathrm{MJ} \mathrm{kg}^{-1}[27,28]$ is not quite as high as specific extracted algal oils (which can even marginally exceed petroleum oil energy density of $\sim 42 \mathrm{MJ} \mathrm{kg}^{-1}$ ), conversion efficiencies of $\sim 40 \mathrm{wt} \%$ currently to perhaps $\sim 50 \mathrm{wt} \%$ as a future target show potential for this method. Nutrient recycling is also possible with this method, but not all nutrients can be retained and the minimisation of nitrogen in biocrude output is an important consideration to reduce $\mathrm{NO}_{x}$ emissions from algae fuels [28], as is reduction of sulphur for $\mathrm{SO}_{x}$. The provision of biomass low in nitrogen and sulphur enhances biocrude quality while the use of catalysts can improve the quality of biocrude output [57] however, the economics and resource sustainability of this approach need to be properly examined. The removal of valuable nitrogenous components of the biomass in fact theoretically improves efficiencies in the biocrude process while adding to the total value of the biomass. Hydrothermal carbonisation and hydrothermal gasification technologies also exist but utilising these production strategies for algal biomass faces strong competition from the continued abundance of cheap coal and natural gas, though it is of note that it is estimated that of the 2850 billion tonnes of the world's total indicated fossil fuel reserves, only $\sim 600$ billion tonnes $(\sim 21 \%)$ can be extracted to stay within this $2^{\circ} \mathrm{C}$ safe limit [20].

Other methods of processing that can utilise wet biomass such as microwave pyrolysis are also worth investigation [58], while in microalgae, naturally occurring and genetically engineered oil secretion systems are also being studied for their potential $[59,60]$. The extraction of secreted oils from semi-continuous culture has many benefits but the 'milking' of extracellular lipids can require additional costs also (e.g. more complex bioreactors and/or agents to prevent degradation of secreted oils), and the economics of this strategy are yet to be properly examined.

Costs of algae fuel feedstocks are still higher than conventional petroleum but advancement in the last decade has been strong, and well configured production models for algal fuels can potentially achieve positive EROI (potentially up to 10x) and carbon neutrality. Although at full scale an algal fuels industry might not be capable of providing more than $10-20 \%$ of global fuel due to resource constraints $\left(\mathrm{CO}_{2}\right.$, water, and nutrients), this is nonetheless a highly desirable outcome.

\section{Future potential}

For an expanding algae industry there is potential for further advancement in biology (strain development, engineering, crop protection and population management), engineering (improved growth systems, downstream processing, and technology integration for improved efficiency and lower costs), business and economics (markets for new products, contributing to stabilisation of energy security), and social aspects (anticipated higher valuation of renewable production systems)

Most algae production industries have traditionally produced only a small number of species commercially (dominant share from 6 microalgal species and 10 macroalgal species, Table 2) but capacity to reliably cultivate a wider range of species is increasing (e.g. large scale cultivation of Scenedesmus by Sapphire Energy (www.sapphireenergy. com) and Tetraselmis by Muradel (www.muradel.com)). Total algae biodiversity is very large (over 8,000 species of macroalgae and over 30,000 species of microalgae) relative to terrestrial crops utilised in conventional agriculture, and this remains an untapped and relatively unexplored bioresource $[29,61,62]$.

Algae present a promising avenue for continued development of high efficiency systems to convert solar energy to hydrocarbon fuels, including the generation of more complex non-fuel bioproducts and other environmental applications. Solazyme has been a pioneer in the production of a range of specialty HVPs from algae, and while generally this and the production of mid value products (MVPs) like omega-3 oils for nutraceuticals markets (e.g. from Schizochytrium and Cryphecodinium) has utilised heterotrophic production, photoautotrophic production systems (e.g. omega-3 EPA from Nannochloropsis [38]) are approaching commercial reality. Algal potential for production of bulk protein and amino acids is being investigated for livestock feed markets, and also for renewable chemicals $[46,63,64]$.

\section{Conclusion}

Macro- and microalgal fuel alternatives have advanced rapidly, but they still require further development before price parity with conventional oil can be achieved. The key challenge remains biomass productivity, as feedstock value is the key driver in all production models. Hydrothermal processing of whole biomass, advanced production strategies for specific oils, and integration of bioproduct

\begin{tabular}{|c|c|c|}
\hline Products & Macroalgae & Microalgae \\
\hline Whole food products & $\begin{array}{c}\text { Porphyra (nori) } \\
\text { Undaria (wakame) } \\
\text { Saccharina (kombu) }\end{array}$ & Spirulina, Chlorella \\
\hline Nutraceuticals & $\begin{array}{c}\text { Undaria for fucoidans } \\
\text { Sargassum for fucoidans } \\
\text { Ulva for ulvans }\end{array}$ & $\begin{array}{l}\text { Dunaliella for } \beta \text {-carotene } \\
\text { Haematococcus for astaxanthin } \\
\text { Schizochytrium for DHA } \\
\text { Crypthecodinium for DHA }\end{array}$ \\
\hline Aquaculture feeds & Ascophyllum & Isochrysis, Chaetoceros, Tetraselmis, Thalassiosira, Pavlova \\
\hline Phycocolloids & $\begin{array}{c}\text { Saccharina for alginates } \\
\text { Kappaphycus for carrageenans } \\
\text { Eucheuma for carrageenans } \\
\text { Gracilaria for agar }\end{array}$ & - \\
\hline Agriculture & $\begin{array}{l}\text { Ascophyllum for animal supplements } \\
\text { Ascophyllum for fertilisers } \\
\text { Ecklonia for fertilisers }\end{array}$ & - \\
\hline
\end{tabular}

Table 2: Conventional examples of commercial production systems for macro- and micro-algae. 
Citation: Stephens E, de Nys R, Ross IL, Hankamer B (2013) Algae Fuels as an Alternative to Petroleum. J Pet Environ Biotechnol 4: 148. doi:10.4172/2157-7463.1000148

outputs in biorefinery models can then each assist in development of sustainable systems. With a low level of investment into this early technology set ( US\$1-2 billion to date), relative to fossil fuels (US\$ trillions per year), the production of renewable fuel from algae is largely unexplored from an economic perspective. Given the challenge of minimising $\mathrm{CO}_{2}$ emissions, increasing fuel security through distributed systems while providing a more sustainable fuel source to support economic development, serious questions should not only be asked at the scientific level, but also at the level of policy.

\section{Acknowledgements}

The authors would like to thank Dr Liam Wagner for advice on energy related economics issues. Ben Hankamer gratefully acknowledges the financial support of the Australian Research Council (LP0883380) as well as funding from a National and International Research Alliance Project (NIRAP) gran supported by Queensland State Government and project partners (KBR, Neste Oil, Siemens, Cement Australia, The University of Queensland, University of Bielefeld and Karlsruhe Institute of Technology). Rocky de Nys acknowledges the support of the Australian Renewable Energy Agency (ARENA), the Advanced Manufacturing Cooperative Research Centre (AMCRC) funded through the Australian Government's Cooperative Research Centre Scheme, and MBD Energy for supporting the Macroalgal Biofuels and Bioproducts - High Energy Algal Fuels Program.

\section{References}

1. BP (2012) Statistical Review of World Energy June 2012

2. Stocker TF (2013) Climate change. The closing door of climate targets. Science 339: $280-282$.

3. Stephens E, Ross IL, Hankamer B (2013) Expanding the microalgal industry continuing controversy or compelling case? Curr Opin Chem Biol 17: 444-452.

4. Pimentel D, Marklein A, Toth MA, Karpoff MN, Paul GS, et al. (2009) Food Versus Biofuels: Environmental and Economic Costs. Hum Ecol 37: 1-12.

5. Gomiero T, Paoletti M, Pimentel D (2010) Biofuels: Efficiency, Ethics, and Limits to Human Appropriation of Ecosystem Services. J Agric Environ Ethics 23: $403-434$

6. Graziano da Silva J (2012) The US must take biofuel action to prevent a food crisis. Financial Times; August 9, 2012.

7. Lewis B, Kambas M (2012) EU Commission to cap food-based biofuels in major shift. Reuters.

8. Seiden A, Hawley NL, Schulz D, Raifman S, McGarvey ST (2012) Long-term trends in food availability, food prices, and obesity in Samoa. Am J Hum Biol 24: $286-295$

9. Dittrick P, Izundu U (2008) OTC speakers highlight offshore industry's future. Oil Gas J 106: 20-25.

10. Tippee B, Poruban S, Dittrick P (2010) OTC speakers highlight offshore industry's future. Oil Gas J 108: 18-22.

11. Duarte CM, Lenton TM, Wadhams P, Wassman P (2012) Abrupt climate change in the Arctic. Nature Climate Change 2: 60-62.

12. IEA (2011) World Energy Outlook 2011. Interntational Energy Agency.

13. EIA (2011) International Energy Outlook 2011.

14. Kerr RA (2011) Energy supplies. Peak oil production may already be here Science 331: 1510-1511.

15. Kerr RA (2012) Oil resources. An oil gusher in the offing, but will it be enough? Science 338: 1139

16. Kerr RA (2012) Oil resources. Technology is turning U.S. oil around but not the worlds. Science 335: 522-523.

17. Kerr RA (2012) Oil resources. Are world oil's prospects not declining all that fast? Science 337: 633

18. Stern N (2006) The Economics of Climate Change. HM Treasury.

19. Metz B, Davidson OR, Bosch PR, Dave R, Meyer LA (eds) (2007) IPCC Fourth Assessment Report of the of the Intergovernmental Panel on Climate Change 2007. Cambridge University Press, Cambridge, New York, USA.
20. Climate Commision (2013) The Critical Decade 2013: Climate Change Science Risks and Responses.

21. IBM (2013) The Battery 500 Project

22. Capo TR, Jaramillo JC, Boyd AE, Lapointe BE, Serafy JE (1999) Sustained high yields of Gracilaria (Rhodophyta) grown in intensive large-scale culture. $J$ Appl Phycol 11: 143-147.

23. Mata L, Schuenhoff A, Santos R (2010) A direct comparison of the performance of the seaweed biofilters, Asparagopsis armata and Ulva rigida. J Appl Phycol 22: $639-644$

24. Frank E, Wang M, Han J, Elgowainy A, Palou-Rivera I (2011) Life-Cycle Analysis of Algal-Based Fuels with the GREET Model. Energy Systems Division, Argonne Laboratory, San Francisco, USA.

25. Uduman N, Qi Y, Danquah MK, Forde GM, Hoadley A (2010) Dewatering of microalgal cultures: A major bottleneck to algae-based fuels. Journal of Renewable and Sustainable Energy 2: 1-15

26. Paul NA, Tseng CK (2012) Chapter 13: Seaweed and Microalgae. In Aquaculture: Farming Aquatic Animals and Plants, J.S. Lucas and P.C. Southgate, Editors, Wiley-Blackwell Publishing Ltd: Oxford.

27. Rowbotham JS, Dyer PW, Greenwell HC, Theodorou MK (2012) Thermochemical processing of macroalgae: a late bloomer in the development of third-generation biofuels? Biofuels 3: 441-461.

28. Biller $P$, Ross $A B$ (2012) Hydrothermal processing of algal biomass for the production of biofuels and chemicals. Biofuels 3: 603-623.

29. Sialve B, Bernet N, Bernard O (2009) Anaerobic digestion of microalgae as a necessary step to make microalgal biodiesel sustainable. Biotechnol Adv 27 409-416.

30. Onwudili JA, Lea-Langton AR, Ross AB, Williams PT (2013) Catalytic hydrothermal gasification of algae for hydrogen production: composition of reaction products and potential for nutrient recycling. Bioresour Technol 127 : $72-80$.

31. Waltz E (2009) Biotech's green gold? Nat Biotechnol 27: 15-18

32. Sun A, Davis R, Starbuck M, Ben-Amotz A, Pate R, et al. (2011) Comparative cost analysis of algal oil production for biofuels. Energy 36: 5169-5179.

33. Stephens E, Ross IL, King Z, Mussgnug JH, Kruse O, et al. (2010) An economic and technical evaluation of microalgal biofuels. Nat Biotechnol 28: 126-128.

34. NRC (2012) Sustainable Development of Algal Biofuels. National Academies Press.

35. NRC (2008) Water Implications of Biofuels Production in the United States. National Academies Press.

36. de Fraiture C, Giordano M, Liao Y (2008) Biofuels and implications fo agricultural water use: blue impacts of green energy. Water Policy 10: 67-81.

37. Cominelli E, Galbiati M, Tonelli C, Bowler C (2009) Water: the invisible problem Access to fresh water is considered to be a universal and free human right, but dwindling resources and a burgeoning population are increasing its economic value. EMBO Rep 10: 671-676.

38. Caspari M (2012) Algae-the optimal crop \& growth industry for Western Australia, In: 2nd Algae World Australia: Perth, WA, Australia.

39. Murphy CF, Allen DT (2011) Energy-water nexus for mass cultivation of algae. Environ Sci Technol 45: 5861-5868.

40. Venteris ER, Skaggs RL, Coleman AM, Wigmosta MS (2013) A GIS cost mode to assess the availability of freshwater, seawater, and saline groundwater for algal biofuel production in the United States. Environ Sci Technol 47: 48404849 .

41. Bixler HJ, Porse $H$ (2011) A decade of change in the seaweed hydrocolloids industry. J Appl Phycol 23: 321-335.

42. Chopin T, Sawhney M (2010) Seaweeds and their Mariculture. Marine Agronomy, Academic Press: London. p. 216-225.

43. Stephens E, Wagner LD, Ross I, Hankamer B (2012) Microalgal production systems: Global impact of industry scale up. In Microalgal Biotechnology, C. Posten, Editor, De Gruyter: Berlin, USA.

44. Pascual C, Elkind J (2010) Energy security: Economics, Politics, Strategies, and Implications: Brookings Institution Press. 
Citation: Stephens E, de Nys R, Ross IL, Hankamer B (2013) Algae Fuels as an Alternative to Petroleum. J Pet Environ Biotechnol 4: 148. doi:10.4172/2157-7463.1000148

Page 7 of 7

45. World Bank (2011) Annual Report.

46. Jung KA, Lim SR, Kim Y, Park JM (2013) Potentials of macroalgae as feedstocks for biorefinery. Bioresour Technol 135: 182-190.

47. Kraan S (2013) Mass-cultivation of carbohydrate rich macroalgae, a possible solution for sustainable biofuel production. Mitigation and Adaptation Strategies for Global Change 18: 27-46.

48. Mulbry W, Kondrad S, Pizarro C, Kebede-Westhead E (2008) Treatment of dairy manure effluent using freshwater algae: algal productivity and recovery of manure nutrients using pilot-scale algal turf scrubbers. Bioresour Technol 99: $8137-8142$

49. Lundquist TJ, Woertz IC, Quinn NWT, Benemann JR (2010) A Realistic Technology and Engineering Assessment of Algae Biofuel Production. Energy Biosciences Institute, University of California, California, USA.

50. de Paula Silva PH, de Nys R, Paul NA (2012) Seasonal growth dynamics and resilience of the green tide alga cladophora coelothrix in high-nutrient tropical aquaculture. Aquaculture Environment Interactions 2: 253-266.

51. Saunders RJ, Paul NA, Hu Y, de Nys R (2012) Sustainable sources of biomass for bioremediation of heavy metals in waste water derived from coal-fired power generation. PLoS One 7: e36470.

52. Cole AJ, Mata L, Paul NA, de Nys R (2013) Using $\mathrm{CO}_{2}$ to Enhance Carbon Capture and Biomass Applications of Freshwater Macroalgae. Global Change Biology Bioenergy.

53. Pragya N, Pandey KK, Sahoo PK (2013) A review on harvesting, oil extraction and biofuels production technologies from microalgae. Renew Sust Energ Rev 24: 159-171.

54. Gallardo-Rodríguez J, Sánchez-Mirón A, García-Camacho F, López-Rosales L, Chisti Y, et al. (2012) Bioactives from microalgal dinoflagellates. Biotechnol Adv 30: 1673-1684.

55. Jones CS, Luong T, Hannon M, Tran M, Gregory JA, et al. (2013) Heterologous expression of the $\mathrm{C}$-terminal antigenic domain of the malaria vaccine candidate Pfs48/45 in the green algae Chlamydomonas reinhardtii. Appl Microbiol Biotechnol 97: 1987-1995.

56. Tran M, Van C, Barrera DJ, Pettersson PL, Peinado CD, et al. (2013) Production of unique immunotoxin cancer therapeutics in algal chloroplasts. Proc Natl Acad Sci U S A 110: E15-22.

57. Biller P, Riley R, Ross AB (2011) Catalytic hydrothermal processing of microalgae: decomposition and upgrading of lipids. Bioresour Technol 102: 4841-4848.

58. Budarin V, Ross AB, Biller P, Riley R, Clark JH, et al. (2012) Microalgae biorefinery concept based on hydrothermal microwave pyrolysis. Green Chem 14: $3251-3254$
59. Roessler PG, Chen Y, Liu B, Dodge CN (2009) Secretion of Fatty Acids by Photosynthetic Microorganisms. World Patent Application(WO2009/076559A1)

60. Vasudevan V, Stratton RW, Pearlson MN, Jersey GR, Beyene AG, et al. (2012 Environmental performance of algal biofuel technology options. Environ Sci Technol 46: 2451-2459.

61. Gosch BJ, Magnusson M, Paul NA, de Nys R (2012) Total lipid and fatty acid composition of seaweeds for the selection of species for oil-based biofuel and bioproducts. Global Change Biology Bioenergy 4: 919-930.

62. Georgianna DR, Mayfield SP (2012) Exploiting diversity and synthetic biology for the production of algal biofuels. Nature 488: 329-335.

63. Chang HN, Kim NJ, Kang J, Jeong CM (2010) Biomass-derived volatile fatty acid platform for fuels and chemicals. Biotechnology and Bioprocess Engineering 15: 1-10.

64. Lammens TM, Franssen MCR, Scott EL, Sanders JPM (2012) Availability of protein-derived amino acids as feedstock for the production of bio-based chemicals. Biomass Bioenerg 44: 168-181.

65. Google Inc. (2013) Google Earth v7.1.1.1580.

66. Photo courtesy of Solar Biofuels Research Centre University of Queensland (2013).

67. Magnusson, M, Mata, L, de Nys, R and Paul, NA (2013) Biomass, Lipid and Fatty Acid Production in Large-Scale Cultures of the Marine Macroalga Derbesia tenuissima.

68. Photo courtesy of Centre for Sustainable Tropical Fisheries and Aquaculture JCU.

69. Neori A, Msuya FE, Shauli L, Schuenhoff A, Kopel F, et al. (2003) A nove three-stage seaweed (Ulva lactuca) biofilter design for integrated mariculture. J Appl Phycol 15: 543-553.

70. Langdon C, Evans F, Demetropoulos C (2004) An environmentally-sustainable, integrated, co-culture system for dulse and abalone production. Aquacult Eng 32: $43-56$.

71. Kumari P, Bijo AJ, Mantri VA, Reddy CR, Jha B (2013) Fatty acid profiling of tropical marine macroalgae: an analysis from chemotaxonomic and nutritional perspectives. Phytochemistry $86: 44-56$.

72. Chisti Y (2007) Biodiesel from microalgae. Biotechnol Adv 25: 294-306.

73. Lawton RJ, de Nys R, Paul NA (2013) Selecting Reliable and Robust Freshwater Macroalgae for Biomass Applications. PLOS One 8: e64168.

74. Illman AM, Scragg AH, Shales SW (2000) Increase in Chlorella strains calorific values when grown in low nitrogen medium. Enzyme Microb Tech 27: 631-635.
Citation: Stephens E, de Nys R, Ross IL, Hankamer B (2013) Algae Fuels as an Alternative to Petroleum. J Pet Environ Biotechnol 4: 148. doi:10.4172/21577463.1000148
Submit your next manuscript and get advantages of OMICS Group submissions

Unique features:

- User friendly/feasible website-translation of your paper to 50 world's leading languages

Audio Version of published paper

Digital articles to share and explore

Special features:

250 Open Access Journals

20,000 editorial team

21 days rapid review process

Quality and quick editorial, review and publication processing

Indexing at PubMed (partial), Scopus, EBSCO, Index Copernicus and Google Scholar etc

Sharing Option: Social Networking Enabled

Authors, Reviewers and Editors rewarded with online Scientific Credits

Better discount for your

Submit your manuscript at: http://www.editorialmanager.com/environsci 